\title{
DOSSIÊ: A TRADUÇÃO NO ENSINO E NA APRENDIZAGEM DE LÍNGUAS ESTRANGEIRAS
}

\author{
Maria Cristina Reckziegel Guedes EVANGELISTA ${ }^{1}$ \\ Paula Tavares PINTO ${ }^{2}$ \\ Odair Luiz NADIN ${ }^{3}$
}

\section{APRESENTAÇÃO}

A Revista EntreLínguas tem como objetivo "Publicar artigos, relatos de experiências, resenhas críticas e entrevistas de pesquisadores nacionais e internacionais sobre ensino e aprendizagem de Línguas Estrangeiras Modernas (LEM), com o fito de promover o debate sobre os processos teórico-metodológicos do ensino de LEM.”

Nesse contexto, apresentamos o volume temático da Revista EntreLínguas (v.3, n. 2, jul./dez. 2017), sobre o tema "A tradução no ensino e na aprendizagem de línguas estrangeiras". Esse tema ainda é alvo de controvérsias e continua sendo um tabu para muitos professores de línguas estrangeiras e pesquisadores, apesar dos estudos sobre ele nunca terem sido interrompidos, como mostram, por exemplo, a compilação de referências bibliográficas elaborada por Ridd (2009) e o amplo estudo sobre esse tema no ensino de línguas estrangeiras na União Europeia, preparado por Pym; Malmkjær e Gutiérrez-Colón Plana (2013).

Entre os trabalhos já publicados, observa-se uma tendência a apresentar primeiramente uma retrospectiva sobre os métodos e abordagens de ensino de línguas estrangeiras, seguida da justificativa para o uso da tradução, como mostram os seguintes trabalhos, apresentados em ordem cronológica crescente: Terra (2010); Tecchio; Bittencourt (2011); Briks (2012), Liberatti (2012); Souza Corrêa (2014), entre outros. Os artigos deste volume voltam-se principalmente para a discussão em nível posterior a

\footnotetext{
${ }^{1}$ Universidade Estadual Paulista (Unesp), Faculdade de Ciências e Letras, Araraquara - SP - Brasil. Professora do Departamento de Letras Modernas. E-mail: macrisevangelista@ @fclar.unesp.br.

${ }^{2}$ Universidade Estadual Paulista (Unesp), Instituto de Biociências, Letras e Ciências Exatas, São José do Rio Preto - SP - Brasil. Professora do Departamento de Letras Modernas. E-mail: paula@ibilce.unesp.br. ${ }^{3}$ Universidade Estadual Paulista (Unesp), Faculdade de Ciências e Letras, Araraquara - SP - Brasil. Professor Doutor do Departamento de Letras Modernas. E-mail: odairnadin@ fclar.unesp.br.
} 
essa fase de justificativas, apontando razões concretas para a utilização da tradução e algumas maneiras de inseri-la em contextos de ensino e aprendizagem.

Valdecy Oliveira Pontes e Livya Lea Oliveira Pereira, no artigo Tradução funcionalista e variação linguística: o uso de sequência didática no ensino de línguas, relatam sobre a elaboração de uma sequência didática na qual são traduzidos trechos de peças teatrais de diferentes países hispânicos, tomando por foco as formas de tratamento do espanhol e do português.

Elisa Figueira de Souza Corrêa apresenta o artigo A tradução pedagógica: experimentos e exercícios para uso em aula e postula que a habilidade tradutória pode ser colocada junto às quatro habilidades tradicionais, ler, escrever, falar e compreender auditivamente, e, deste modo, contribuir para o aumento de consciência linguística do aprendiz.

Sinara de Oliveira Branco e Luciana Soares dos Santos elaboraram o artigo $O$ uso de atividades de tradução intersemiótica e interlingual em uma sala de aula de língua inglesa como $L E$, no qual procuram evidenciar a eficácia do uso da tradução como ferramenta de ensino de língua inglesa, tomando por base as categorias de tradução propostas por Jakobson (1958/2000) e seguindo uma metodologia de natureza qualitativa e de pesquisa-ação.

Aline Cantarotti apresenta Data-driven learning, tradução e Secretariado Executivo: proposta de abordagem de auto-estudo para aprendizes de inglês. Sua pesquisa aproxima a metodologia de trabalho da linguística de corpus ao âmbito da aprendizagem de língua estrangeira, levando o aprendiz a descobrir por si próprio as características léxico-gramaticais da língua que estuda.

Viviane Cristina Poletto Lugli, autora do artigo A expressão de verbos modais na tradução do gênero decisão: contribuições para o ensino de língua estrangeira, propõe a comparação entre excertos de trechos desse gênero em português, espanhol e inglês, unindo os estudos da língua estrangeira e dos gêneros textuais.

Paolo E. Balboni, em Tradução na aprendizagem de línguas: uma abordagem 'Para quê', busca avaliar como a tradução pode trazer benefícios às diferentes habilidades relacionadas às competências linguística, extralinguística, sócio-pragmática e intercultural dos aprendizes de língua estrangeira.

Bruna Di Sabato e Bronwen Hughes, no artigo Tradução e ensino de língua estrangeira, um ponto de vista teórico e prático: o cenário italiano, discorrem sobre o 
papel da tradução em currículos de universidades italianas e apontam algumas atividades de tradução que podem ser desenvolvidas pelos aprendizes de línguas.

Joselma Maria Noal; Artur Emílio Alarcon Vaz e Daniele Corbetta Pilleti trazem discussões sobre A tradução literária no ensino de línguas. Sua pesquisa parte da tradução de contos da escritora argentina Juana Manuela Gorriti pelos aprendizes e analisa dificuldades na tradução, relacionadas aos âmbitos gramatical, lexical e estilístico, mostrando que esse trabalho também aproxima os aprendizes de questões culturais.

Krisztina Zimanyi apresenta o artigo Caminhos para o Ensino de tradução na aula de língua estrangeira: uma proposta para a tradução audiovisual de Coraline em aulas de inglês como LE / ESOL. As atividades propostas pela autora incluem a tradução intralingual, interlingual e intersemiótica (Jakobson, 1959/2000) e buscam motivar os aprendizes, promovendo sua autonomia.

Glauber Lima Moreira apresenta a entrevista realizada com a professora Dra. Janet DeCesaris da Universitat Pompeu Fabra (UPF), intitulada $O$ papel da tradução no ensino de línguas estrangeiras modernas. A entrevistada entende a tradução principalmente como uma ferramenta didática, que permite a comparação entre as línguas, promovendo a conscientização sobre questões linguísticas.

\section{REFERÊNCIAS}

BRIKS, F. J. P. Tradução: Ferramenta eficaz no ensino-aprendizagem de línguas estrangeiras para o aluno do ensino superior. In: Belas Infiéis, v. 1, n. 1, p. 153-167, 2012.

JAKOBSON, R. On linguistic aspects of translation. In: VENUTI, L. The Translation Studies Reader. London/New York: Routledge, 113-118, 1959/2000.

LIBERATTI, E. A tradução na sala de aula de LE: (des)construindo conceitos. In: Entrepalavras, Fortaleza, ano 2, v. 2, n. 1, p. 175-187, 2012.

PYM, A.; GUTIÉRREZ-COLÓN PLANA, M. d. M.; MALMKJAER, K. Translation and language learning: the role of translation in the teaching of languages in the European Union. A Study. Directorate-General for Translation - European Commission. 15 July 2013.

RIDD, M. Bibliografia de referência sobre tradução no ensino e aprendizagem de línguas. In: Horizontes de Linguística Aplicada, v. 8, n. 2, p. 255-296, 2009. 
SOUZA CORRÊA, E. F. de. A língua materna e a tradução no ensinoaprendizagem de língua não-materna: uma historiografia crítica. Tese de doutorado. PUC, Rio de Janeiro, 2014.

TECCHIO, I.; BITTENCOURT, M. J. G. A tradução no ensino-aprendizagem de línguas estrangeiras. In: Revista Magistro, v. 2, n. 1, p. 152-165, 2011. Disponível em:

TERRA, M. R. Tradução \& aprendizado de língua estrangeira: o ponto de vista do aluno. Trab. Ling. Aplic., Campinas, v. 49, n.1, p. 69-85, jan./jun. 2010.

\section{Como referenciar esta apresentação}

EVANGELISTA, Maria Cristina Reckziegel Guedes.; PINTO, Paula Tavares.; NADIN, Odair Luiz. Apresentação. Dossiê: A tradução no ensino e na aprendizagem de línguas estrangeiras. Rev. EntreLínguas, Araraquara, v.3, n.2, p. 141-144, jul./dez. 2017. Disponível em: <https://doi.org/10.29051/rel.v3.n2.2017.10796>. E-ISSN: 2447-3529. 